\title{
Umbilical lines in a sick, extremely low birth weight infant: clinical quandary of $X$-ray images
}

\author{
Jiahui Li, ${ }^{1}$ Juin Yee Kong, 1,2,3 Teo Eu-leong Harvey James, 1,2,3 Suresh Chandran 1,2,3
}

'Duke - NUS Medical School, Singapore

${ }^{2}$ NUS YLL School of Medicine, Singapore

${ }^{3}$ Department of Neonatology and Diagnostic and Interventional Imaging, KK Women's and Children's Hospital, Singapore

\section{Correspondence to}

Dr Suresh Chandran, schandran1312@yahoo.co.uk

Accepted 7 June 2016
CrossMark

To cite: Li J, Kong JY, James TELH, et al. BMJ Case Rep Published online: [please include Day Month Year] doi:10.1136/bcr-2016215275

\section{DESCRIPTION}

A female infant weighing $530 \mathrm{~g}$ was born at 24 weeks of gestation. Antenatal ultrasounds were unremarkable. She was intubated and given surfactant at birth. Umbilical venous (UV) and arterial (UA) catheters were inserted through the identified separate vascular orifices. Postinsertion X-ray showed one catheter entering the left liver lobe and the other entering the right atrium (figure 1). The deeper inserted catheter was withdrawn but subsequently migrated into the hepatic vein (figure 2). Neither catheter showed a descent to the pelvis before ascending, as would have been observed in the UA; it is speculated that they were in the UV, indicating the persistence of right umbilical vein (PRUV). The catheter entering the hepatic vein was removed and a new catheter was inserted through the third vascular orifice of the umbilicus. Ultrasound imaging of the UV catheter showed the UV tip in the left portal vein, instead of being in

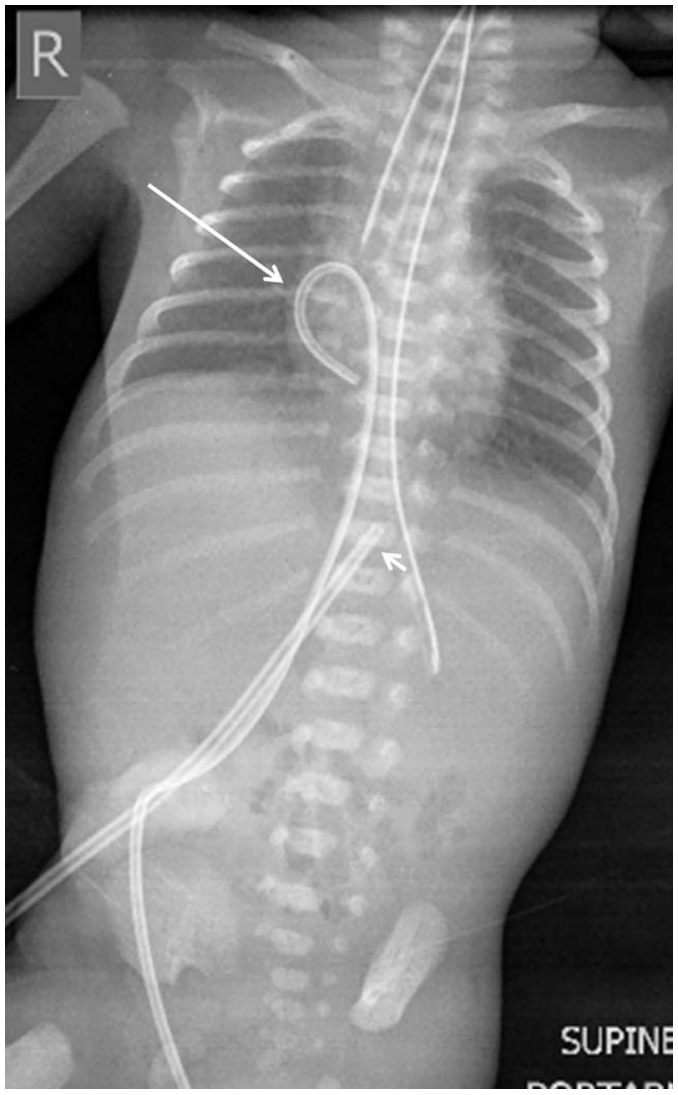

Figure 1 A UV catheter with its distal end coiled in the right atrium (arrow). A second UV catheter is seen more inferiorly, with its tip situated in the umbilical vein.

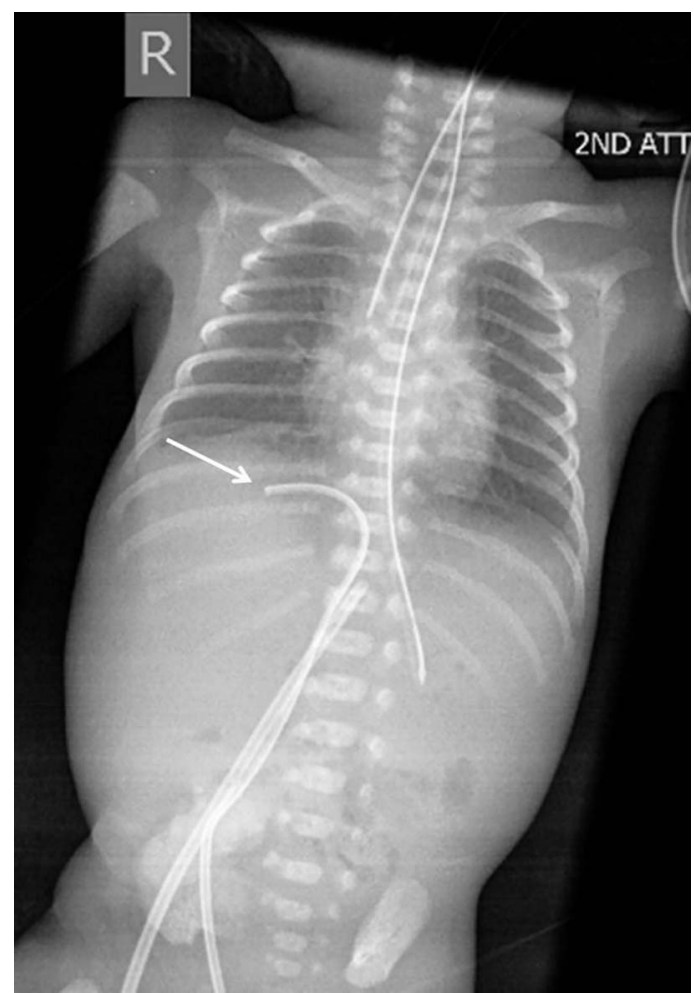

Figure 2 After the initial radiograph, shown in figure 1 the more superiorly placed UVC was withdrawn slightly. Its tip was then seen to point towards the right (long arrow), possibly within the hepatic vein. UVC, umbilical venous catheter.

the ductus venosus, and it was repositioned. Final $\mathrm{X}$-ray showed the UV catheter in the ductus, and the UA catheter proceeding inferiorly and curving cephalad to enter the aorta (figure 3). Later attempts to delineate the path of PRUV, using ultrasound, were unsuccessful, due to the rapid collapse being a vein. Echocardiography and cranial ultrasounds were unremarkable.

This is the first report of a quandary related to PRUV and UV line. A single umbilical artery, the most common PRUV-associated anomaly, was present in this case. ${ }^{1}$ PRUV can be either intrahepatic or extrahepatic. Absence of major organ anomalies in this case suggests an intrahepatic type, which drains into the ductus venosus. ${ }^{2}{ }^{3}$

Contributors $\mathrm{JL}$ and JYK wrote up the case, THJ provided the radiology report, and SC edited and finalised the case report.

Competing interests None declared.

Patient consent Obtained.

Provenance and peer review Not commissioned; externally peer reviewed. 


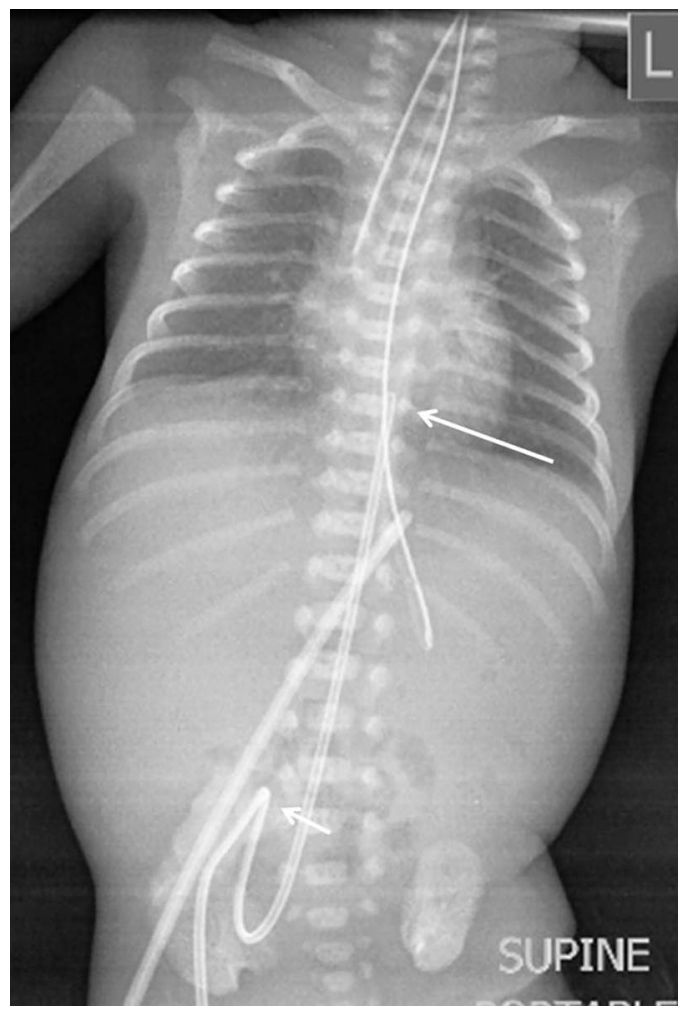

\section{Learning points}

- The right umbilical vein disappears around 7 weeks of gestation, hence if it persists in the fetal ultrasound scan, screen for cardiac, skeletal, cerebral, urological and gastrointestinal anomalies. ${ }^{1}$

- X-ray images showing two catheters in the right half of the abdomen after insertion through two separate vascular orifices in the umbilicus, raise suspicion of persistence of right umbilical vein.

- When in doubt, ultrasound during line placement can delineate the path of the catheters, confirming their position in the vascular system.

\section{REFERENCES}

1 Leal DB, Maggiolini M, Bianchi A. Prenatal diagnosis and postnatal follow-up of patients with persistent right umbilical vein. Donald School J Ultrasound Obstet Gynecol 2012;6:104-8.

2 Wolman I, Gull I, Fait G, et al. Persistent right umbilical vein: incidence and significance. Ultrasound Obstet Gynecol 2002;19:562-4.

3 Blazer S, Zimmer EZ, Bronshtein M. Persistent right umbilical vein in the fetus: a benign anatomic variant. Obstet Gynecol 2000;95:433-6.

Figure 3 A third radiograph was obtained after the malpositioned UVC was removed and an UAC was put in place. The UAC takes an inferior turn into the pelvis on entering the umbilicus to enter the common iliac artery (short arrow). It then turns superiorly to end with its tip situated within the aorta at the level of the T8 vertebral body (long arrow). UAC, umbilical arterial catheter.

Copyright 2016 BMJ Publishing Group. All rights reserved. For permission to reuse any of this content visit http://group.bmj.com/group/rights-licensing/permissions.

BMJ Case Report Fellows may re-use this article for personal use and teaching without any further permission.

Become a Fellow of BMJ Case Reports today and you can:

- Submit as many cases as you like

- Enjoy fast sympathetic peer review and rapid publication of accepted articles

- Access all the published articles

- Re-use any of the published material for personal use and teaching without further permission

For information on Institutional Fellowships contact consortiasales@bmjgroup.com

Visit casereports.bmj.com for more articles like this and to become a Fellow 